\title{
América latina: cooperación en seguridad y defensa en un contexto de cambios globales
}

\section{Latin america: security and defence cooperation in a global change context}

\author{
Francisco Rojas Aravena ${ }^{1}$ \\ University for Peace (Costa Rica)
}

Recibido: 30-05-14

Aprobado: 15-06-14

\section{Resumen}

Este año 2014 conmemoramos los 100 años de la I Guerra Mundial. Los últimos acontecimientos en Europa indican que no se han aprendido las más importantes lecciones que esta guerra dejó, en particular en lo relativo al multilateralismo, la resolución de conflictos, al tratamiento al terrorismo y a las migraciones forzadas. Lo anterior se produce en un contexto de cambios globales que incide en los grandes derroteros del sistema internacional. América Latina y el Caribe contribuyen en la actualidad de manera sustantiva a la Paz y la estabilidad global $^{2}$.

Palabras-clave: América Latina, Seguridad y Defensa, multilateralismo, cambios globales

\footnotetext{
Abstract

This year 2014 we commemorate the 1st century of the First World War. Recent events in Europe suggest that the most important lessons that this war left haven't been learned, particularly in regard to multilateralism, conflict resolution, treatment of terrorism and forced migration. This occurs in a context of global

${ }^{1}$ (f.rojas@upeace.org) Francisco Rojas Aravena es rector de la Universidad para la Paz, Costa Rica. Doctor en Ciencias Políticas, Universidad de Utrecht, Holanda. Fue el anterior Secretario General de FLACSO (2004-2012).

${ }^{2}$ Agradezco la colaboración de Diana Guardia asistente de investigación. En este trabajo retomo y actualizo algunas de las ideas que he reflexionado e investigado sobre la región latinoamericana y caribeña y la seguridad internacional y regional.
} 
change that affects the paths of the international system. Latin America and the Caribbean currently contribute substantively to global peace and stability.

Key-words: Latin America, Security and Defence, multilateralism, global changes.

\section{Cambios Globales ${ }^{3}$}

En el último cuarto de siglo el sistema internacional entró en un acelerado proceso de cambios, que se manifiestan tanto en los grandes actores internacionales, las superpotencias, como en los países más pequeños. Un primer ciclo se inició con el fin de la Guerra Fría que, generó los más importantes cambios en el sistema internacional en 50 años. La desaparición de la URSS y del campo socialista cerró un ciclo del sistema internacional. Parecía emerger una potencia global con un poder incontestable. En menos de una década irrumpió otro cambio. Una nueva etapa se produjo cuando surgió otro tipo de amenazas que desafió de forma diferente este poder: las amenazas asimétricas. La crisis generada por el terrorismo transnacional de alcance global a partir del 11 de septiembre volvió a cambiar las prioridades transformando la seguridad en el tema prioritario. Se patentizaron nuevas vulnerabilidades para las cuales el poder militar tradicional no era efectivo. La superpotencia podía ser atacada en su territorio. Lo anterior involucró a Estados Unidos en dos guerras que se empantanaron. En forma paralela el otro resultado fue el bloqueo del sistema multilateral y el debilitamiento de las Naciones Unidas. Lo característico fue la guerra contra el terrorismo y la militarización de las respuestas internacionales de la gran potencia. Un nuevo cambio profundo se abrió con la crisis financiero-económica de 2008, surgida en Estados Unidos y que afecta centralmente a la Unión Europea, y cuyas consecuencias son globales y han permanecido por más de un quinquenio. El referéndum celebrado en Crimea, mediante el cual la gran mayoría de los ciudadanos votaron a favor de anexar esta península a Rusia, ha generado fuertes tensiones entre Rusia, la Unión Europea y los Estados Unidos. Varios analistas consideran que si este conflicto no se maneja de manera adecuada puede tener grandes implicaciones a nivel mundial y podríamos estar a las puertas de un nuevo ciclo en el que el uso de la fuerza puede estar presente con grandes escaladas de tensiones y graves peligros para la estabilidad global. Por otro lado, el resurgimiento con fuerza de los nacionalismos y de movimientos neo-nazis en Europa generan tensiones políticas no exentas de peligros mayores para la estabilidad política

\footnotetext{
${ }^{3}$ Francisco Rojas, Transformaciones globales y cambios en las relaciones de poder. Impactos en América Latina y el Caribe. Revista Nueva Sociedad Nํㅡㄹ 246, julio-agosto de 2013, ISSN: 0251-3552, En: www.nuso.org.
} 
en esa región y con ello un desborde más amplio al sistema internacional.

Las relaciones de poder están cambiando de manera rápida. Los esquemas de gobernanza global no están dando los resultados esperados y con ello el surgimiento de crisis y situaciones de inestabilidad es recurrente. La falta de previsibilidad debilita las relaciones y dificulta la concertación sobre bienes públicos globales. El conjunto de fenómenos que marcan los últimos 25 años evidencian los cambios en las relaciones de poder, en un ambiente internacional de gran incertidumbre y altas desconfianzas. La alta interdependencia global y en las regiones complejiza el cuadro los procesos y las relaciones de poder. La incertidumbre es la característica de la actual coyuntura.

Con la globalización, la interdependencia es la norma, situación que tiene aspectos positivos pero otros muy negativos. Las sociedades, en este contexto, hoy se conocen más y se relacionan más, lo que a nivel social y cultural ha generado mayor riqueza y una más amplia pluralidad; pero al mismo tiempo las amenazas se han mundializado y los peligros y riesgos se han transnacionalizado. Se requieren nuevos mapas conceptuales que permitan comprender los diferentes tránsitos hacia una nueva Era, hacia un mundo postoccidental y la emergencia global de "otras" visiones, perspectivas y valores en el contexto de un fuerte entrelazamiento de las economías y tendencias al uso de bienes de consumo globales. El sistema global se mueve además en la dirección de un sistema "post hegemónico". Esta compleja transición afecta a las capacidades, la gestión y la eficiencia de las repuestas - algunas urgentes-a los retos globales.

La institucionalidad multilateral global se encuentra estancada, sin capacidad para producir consensos que den respuestas a los retos globales como el atómico, el medio ambiental, la crisis financiera, la crisis alimentaria y las crisis humanitarias emergentes. Los riesgos globales son cada vez más significativos ${ }^{4}$.

Los temas transnacionales cobran cada vez más gravitación. No existe acuerdo sobre la agenda de reformas del sistema multilateral, ni sobre su principal órgano, las Naciones Unidas. Las capacidades para ejercer una gobernanza global se debilitan. La opción de crear el G-20 no ha funcionado más allá de algunas medidas iniciales. En este mecanismo participan tres países latinoamericanos, pero no participa América Latina como conjunto. México, Brasil y Argentina no se coordinan, no hay un diálogo previo ni acuerdo de posiciones, ni entre ellos ni con el resto de la región, para enfrentar los temas globales. Esta entidad no posee las capacidades para enfrentar una agenda tan amplia y en la que las diferencias son significativas.

${ }^{4}$ Ulrich Beck, La sociedad del riesgo mundial. En busca de la seguridad perdida. Ed. Paidos, Buenos Aires, 2008. pág. 334

Araucaria. Revista Iberoamericana de Filosofía, Política y Humanidades, año 16, n 32. Segundo semestre de 2014. Pp. 203-236. ISSN 1575-6823 e-ISSN 2340-2199 doi: 10.12795/araucaria.2014.i32.11 
En esta etapa de transformaciones sucesivas y de nuevos ejes de gravitación globales y regionales ningún Estado, por poderoso que sea, ni siquiera la superpotencia global, puede dirigir y hegemonizar el sistema internacional, y las respuestas frente a los desafíos y la emergencia de los temas transnacionales requiere de respuestas multilaterales, de acciones coordinadas y asociadas y de un fuerte impulso a la cooperación y cursos de acción concertados. Solo sobre esta base se podrán construir los consensos para gestionar una gobernanza global y reducir los riesgos planetarios y sus expresiones regionales.

Muchas de las transformaciones que se observan en el mundo en la actualidad son fenómenos intermésticos, es decir fenómenos que son simultáneamente globales y domésticos. Las élites políticas y las sociedades han visto desaparecer países y surgir otros. Hay nuevos actores globales.

Desde América Latina y el Caribe no ha surgido ninguna propuesta viable sobre transformaciones del sistema internacional. La región no posee una visión compartida sobre los cambios requeridos para democratizar el sistema global. Ni la región, ni la potencia emergente, Brasil, están en condiciones de ser parte de los "hacedores de reglas". El peso de América Latina en términos cuantitativos se ha reducido desde el origen de la ONU en 1945. Sin concertación regional efectiva, sin una visión compartida sobre la promoción de bienes públicos globales, la incidencia regional no tendrá efectividad. El primer paso es buscar formas de institucionales que posibiliten dar cuenta de las nuevas realidades de poder; en la actualidad la CELAC podría representar esa posibilidad.

\section{Algunos cambios internacionales significativos}

Surgen nuevos globalizadores con la emergencia del mundo en desarrollo en el ámbito económico, particularmente de China e India y más en general de los llamados BRICSA, (Brasil, Rusia, India, China y Sudáfrica). En la década de los noventa las economías desarrolladas representaban el mayor peso en la economía internacional. Desde poco después de 2000 y, particularmente al término de esta década, lo que se observa es que los países en desarrollo son los que representan el mayor peso y relevancia en la economía mundial, tendencia que se incrementará en las próximas décadas; situación que la crisis de los países desarrollados acelerarás.

${ }^{5}$ CEPAL. Balance Preliminar de la Economía de América Latina y el Caribe. 2012. ONU/CEPAL. Santiago. Chile 


\section{Gráfico 1. El crecimiento global es liderado por economías no-OECD}

Figure 1.9. Global growth continues be led by the non-OECD economies Contribution to annualised quarterly world real GDP growth

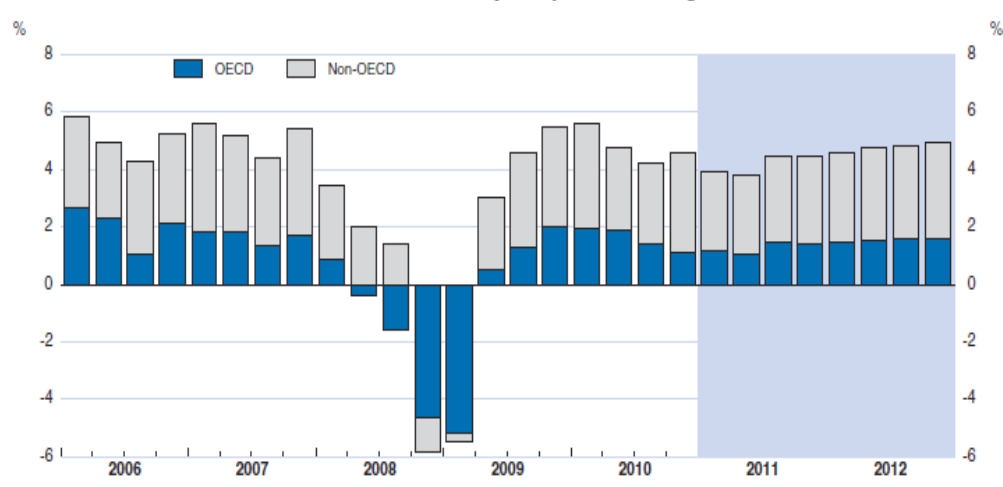

Note: Calculated using moving nominal GDP weights, based on national GDP at purchasing power parities. Source: OECD Economic Outlook 89 database.

Fuente: Centro de Desarrollo OCDE Perspectivas Económicas Globales 2010. Tomado de la presentación de Christian Daude "Perspectivas de Desarrollo en América Latina" en el Seminario "Desarrollo en América Latina: Visiones y Coincidencias", organizado por FLACSO. Buenos Aires, 31 de mayo, 2011.

El rápido ascenso de China como potencia de primer orden es de los cambios más importantes del siglo XXI. Junto a ello un desplazamiento de los ejes de gravitación comerciales, financieros, de inversiones, así como los estratégicos-militares a la Cuenca del Asia-Pacífico. En consecuencia, el peso del Atlántico ha disminuido considerablemente.

El surgimiento de una "nueva clase media" es uno de los hechos económicos y sociales más significativos en el contexto de cambios globales ${ }^{6}$. Ello ocurre en especial en los países en desarrollo. El crecimiento económico en el mundo en desarrollo produce cambios en las demandas de los mercados mundiales. Los mayores cambios se están produciendo en China, India, Rusia, Brasil y México. En el caso Latinoamericano, entre 2000 y 2009 la desigualdad se redujo en 13 de los 17 países de la región para los que se tienen series comparables ${ }^{7}$.

La crisis financiera y económica iniciada en Estados Unidos en el año 2008 se ha trasladado con gran fuerza a Europa. Es una profunda crisis económica, de identidad y de modelo de desarrollo la Unión Europea. La UE se fragmenta

\footnotetext{
${ }^{6}$ PNUD, Informe sobre Desarrollo Humano 2013. El ascenso del Sur: Progreso humano en un mundo diverso. En: http://www.undp.org/content/dam/undp/library/corporate/HDR/2013GlobalHDR/ Spanish/HDR2013\%20Summary\%20Spanish.pdf

${ }^{7}$ Revista Pensamiento Iberoamericano, $\mathrm{N}^{\circ}$ 10, 2 época, 2012/1. Clases Medias en Sociedades desiguales. (coordinación Rebeca Grynspan y Ludolfo Paramio).
} 
y se polariza. No aparecen políticas convergentes, ni liderazgos consolidados de proyección europea y global. La recuperación tardará; será un proceso que se indica podría tomar al menos una década ${ }^{8}$.

Cambios -por medio de manifestaciones y de guerras civiles- en las estructuras políticas y de las elites en el poder en Oriente Medio, producen la "primavera/revolución árabe", que aún no terminan de decantarse. De ellas emergen con fuerza sentimientos anti-occidentales, en especial antiestadounidenses, y toman fuerza organizaciones políticas con un fuerte sello teocrático musulmán / islamista. En este contexto, el tema nuclear iraní y sus políticas radicales frente a Israel y las de este frente a Irán generan aprensiones de una escalada, incluso militar, de envergadura. El actual conflicto en Siria se ubica en esta dimensión. La crisis en Ucrania, la fragmentación de Crimea y de otras regiones de este país agrava el cuadro.

El Consejo de Seguridad de la ONU se encuentra trabado, sin capacidad de acción efectiva, ni siquiera humanitaria. La inestabilidad en esta región afecta a los precios del petróleo y el gas, y a su impacto en la economía global. Las potencias y los actores estatales con mayor poder, herencia de la II GM, no encuentran fórmulas para integrar a las potencias emergentes y hacer partícipes a los distintos actores estatales que reclaman cambios, y que reconozca los nuevos balances de poder.

El número de conflictos inter-estatales así como el número de muertes por causa de guerras civiles ha disminuido sustantivamente después de la Guerra Fría ${ }^{9}$ (ver gráficos 2 y 3). Sin embargo, esto no ha derivado en un mundo más pacífico ${ }^{10}$. Hoy día los países deben enfrentarse a nuevas amenazas de corte trasnacional que tienen un profundo impacto en la estabilidad de los países, así como en la seguridad de las personas. Si algo ha dejado claro la globalización en los últimos años es que en la actualidad los países se enfrentan a una serie de problemáticas que ningún Estado es capaz de combatir por sí solo. De ahí que estos fenómenos forman parte fundamental de las agendas internacionales, dada la comprensión de la necesidad de cooperación y coordinación conjunta para tener resultados más positivos y efectivos de resolución.

\footnotetext{
${ }^{8}$ En el caso de muchas empresas europeas - de telecomunicaciones, energía, bancos, construcción - sus posibilidades de recuperación están cifradas en el crecimiento que estas tiene en la actualidad en América Latina. Las principales ganancias surgen hoy desde ALyC.

9 Human Security Report Project, Human Security Report 2013. En: http://www.hsrgroup.org/ human-security-reports/2013/text.aspx

${ }^{10}$ Banco Mundial (2011), Crimen y Violencia en Centroamérica. Un Desafio para el Desarrollo. Documento del Banco Mundial. pp 40. En: www.bancomundial.org
} 


\section{Gráfico 2. Promedio de Conflictos Internacionales 1950-2008}

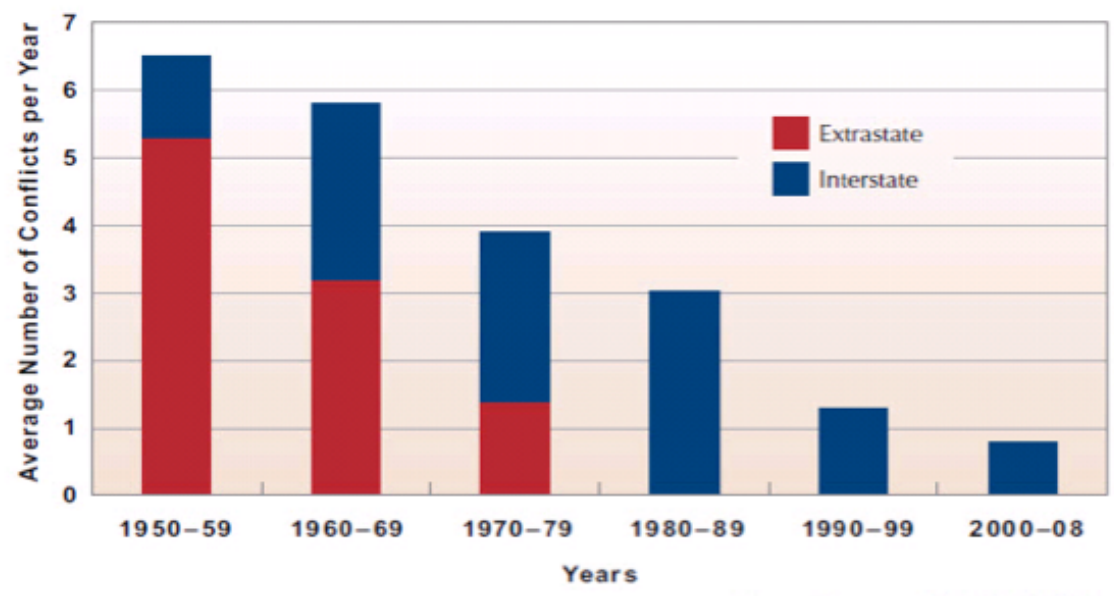

Fuente: Human Security Report 2009-2010

Gráfico 3. Se reducen las muertes por guerras civiles

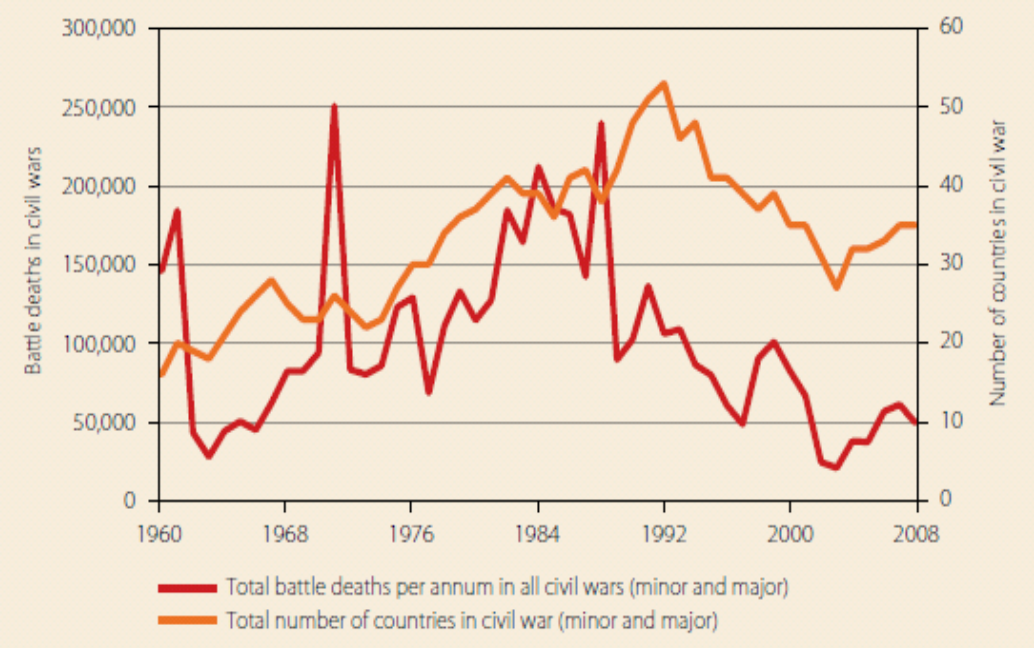

Fuente: Banco Mundial. World Development Report 2011 
El crimen organizado es crecientemente transnacional. La transnacionalización es una consecuencia progresiva de la globalización. En este marco el crimen organizado adquiere una gran sofisticación accediendo al uso de tecnologías de punta y de comunicaciones más fácilmente que los Estados. La ampliación del ámbito operativo de las redes criminales organizadas, resultante de los procesos de globalización financiera y comercial, constituye un caldo de cultivo óptimo para el fortalecimiento de las acciones ilícitas. Las organizaciones criminales operan internacionalmente con tanta solvencia y sofisticación como las empresas transnacionales, pueden vincularse a éstas e incluso competir con ellas en áreas específicas del mercado dada la dualidad de muchas de sus empresas ${ }^{11}$. De hecho hoy constituyen una amenaza seria a las democracias en la región.

\section{Principales cambios en América Latina.}

En este período de incertidumbres globales, América Latina también ha tenido transformaciones muy significativas. Los reajustes de poder y los cambios establecidos en el sistema global tienen consecuencias directas en nuestra región. La más importante es la menor presencia y peso de los Estados Unidos, en especial en la parte sur de la América Latina. El cambio geopolítico principal que se desarrolla desde América Latina es la emergencia de Brasil. Este país continente surge como potencia global y regional; representa un tercio de la población de ALyC y un $43 \%$ del producto regional. Ambas situaciones conllevan un mayor grado de autonomía político-económica y estratégica de Brasil y de la región. Todos los países reafirman sus capacidades soberanas en relación al poder hegemónico y a otros actores extrarregionales.

Nuevos actores externos, tradicionalmente ausentes de la región, en la actualidad adquieren cada vez mayor importancia, en especial las economías emergentes de la región del Asia Pacífico, en particular China e India, con una focalización comercial y económica. A ellas se suma un renovado interés de Rusia por afincar sus vínculos con la región con un énfasis diplomático. Otros actores miran con interés a la región y vuelven a ella, como Gran Bretaña, en forma independiente de la UE. Un nuevo actor es Irán, que ha encontrado un espacio importante en América Latina principalmente por el carácter y forma de respuesta a la globalización, que encuentra coincidencias importantes en algunos de los regímenes políticos latinoamericanos. Irán es una potencia emergente en su región, pero que no ha descuidado los vínculos globales. $\mathrm{Su}$ presencia tiene un peso simbólico más que comercial o como desafío político estratégico a la potencia hegemónica en esta área.

${ }^{11}$ Luis Guillermo Solís y Francisco Rojas Aravena (editores) (2008) Crimen Organizado en América Latina y el Caribe. FLACSO Secretaría General: Catalonia. También en: www.flacso.org 
América Latina, luego de media década perdida (1998-2002), recobró la senda del crecimiento en el año 2003, que se vio interrumpida en el año 2009 a consecuencia de la crisis financiera global. No obstante, los impactos fueron de menor magnitud de los esperados. América Latina continúa su derrotero de crecimiento en los últimos dos años y las tendencias indican que continuará por ese camino, aunque a un ritmo algo menor.

Latinoamérica muestra dos de sus principales activos: a) una región con sistemas democráticos bastante estables y una democracia electoral efectiva; b) es una zona de paz y en un área libre de armas nucleares.

La democracia caracteriza a la América Latina y el Caribe del siglo XXI ${ }^{12}$. El golpe de Estado en Honduras al presidente Manuel Zelaya, la madrugada del 28 de junio de 2009, la tensión policial frente al Presidente de Ecuador Rafael Correa el 30 de septiembre de 2010, fueron condenados de forma unánime y categórica por parte de todos los países de la región. Más allá del debate sobre la legalidad, el desplazamiento del Presidente Fernando Lugo en Paraguay, por la forma y velocidad generó significativas reacciones de repudio, en espacial en Sur América, donde se coincide en que se trató de un "golpe parlamentario". Los países de la región, en el marco de la OEA, han continuado comprometiéndose con la Carta Democrática Interamericana ${ }^{13}$.

\section{Grafico 4.}

\section{Apoyo a la democracia América Latina. 1995/2013}

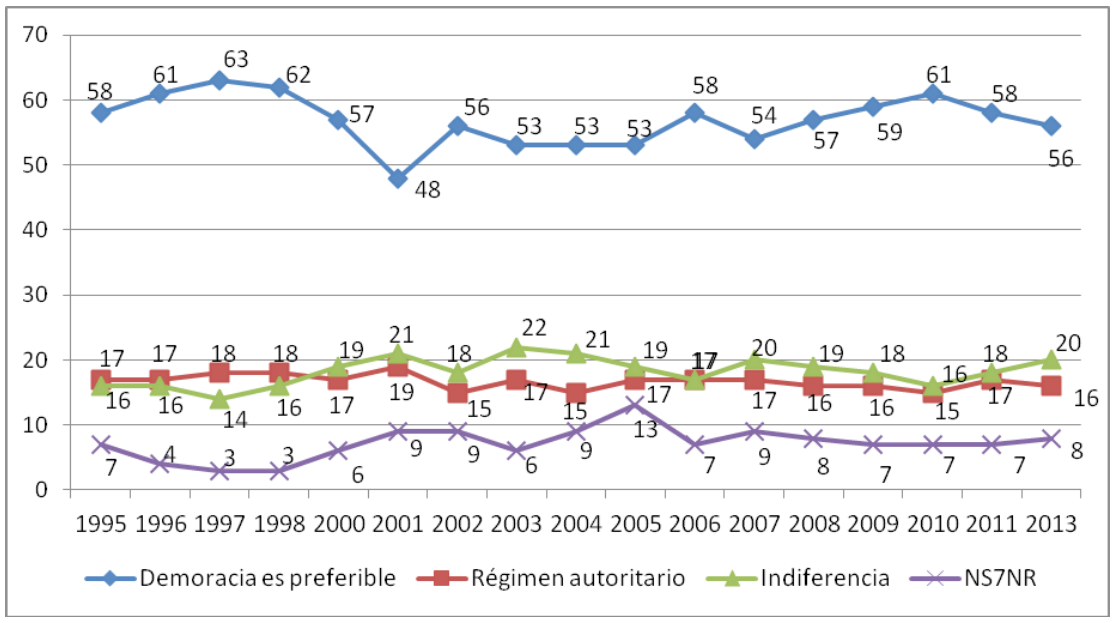

Fuente: Corporación Latinobarómetro. Informe Latinobarómetro 2013. Santiago, Chile

\footnotetext{
${ }^{12}$ PNUD / OEA, Nuestra Democracia, Fondo Cultura Económica, México. 2010. 260pp.

${ }^{13}$ http://www.oas.org/es/
} 
La paz interestatal impera en América Latina, pese a que aún se mantienen importantes contenciosos cuyos orígenes están en el siglo XIX, en la delimitación de las fronteras. A ello se sumaron diferencias en el siglo XX referidas a los temas de delimitación marítima. La mayoría de estos litigios son latentes. Muchos de ellos fueron resueltos por los gobiernos democráticos en negociaciones directas. Los que se han explicitado han buscado los medios judiciales para su resolución. La Corte Internacional de Justicia está resolviendo más de seis litigios. Nada indica que esto pudiese cambiar. Los Estados con fuerzas armadas establecidas desarrollan actividades e iniciativas en el ámbito de las medidas de confianza mutua, para generar mecanismos de prevención. Si bien muchos de ellos son más bien formales, constituyen un instrumento útil en esta materia.

El principal peligro para la paz y la vida de los ciudadanos y ciudadanas de América Latina y el Caribe, no proviene de la probabilidad de una guerra entre Estados. El peligro lo constituyen la violencia y, en particular, los homicidios dolosos. La región es de las más violentas del mundo. Los homicidios constituyen una pandemia, en términos de las definiciones de la Organización Mundial de la Salud (OMS).

Un informe reciente del Banco Mundial ${ }^{14}$, al contextualizar la situación, señala que la población total de Centroamérica es aproximadamente la misma que la de España; sin embargo, en 2006, España registró 336 asesinatos (es decir menos de uno por día) y Centroamérica registró 14.257 asesinatos (casi 40 por día). Todas estas cifras lo que evidencian es que hoy el número de muertos supera al de muertes ocurridas durante el conflicto armado en los años ochenta.

${ }_{14}$ Banco Mundial (2011), Crimen y Violencia en Centroamérica. Un Desafío para el Desarrollo. Documento del Banco Mundial. Pp 40. www.bancomundial.org 


\section{Gráfico 5. Tasa de homicidios por subregión (2012 o dato más reciente)}

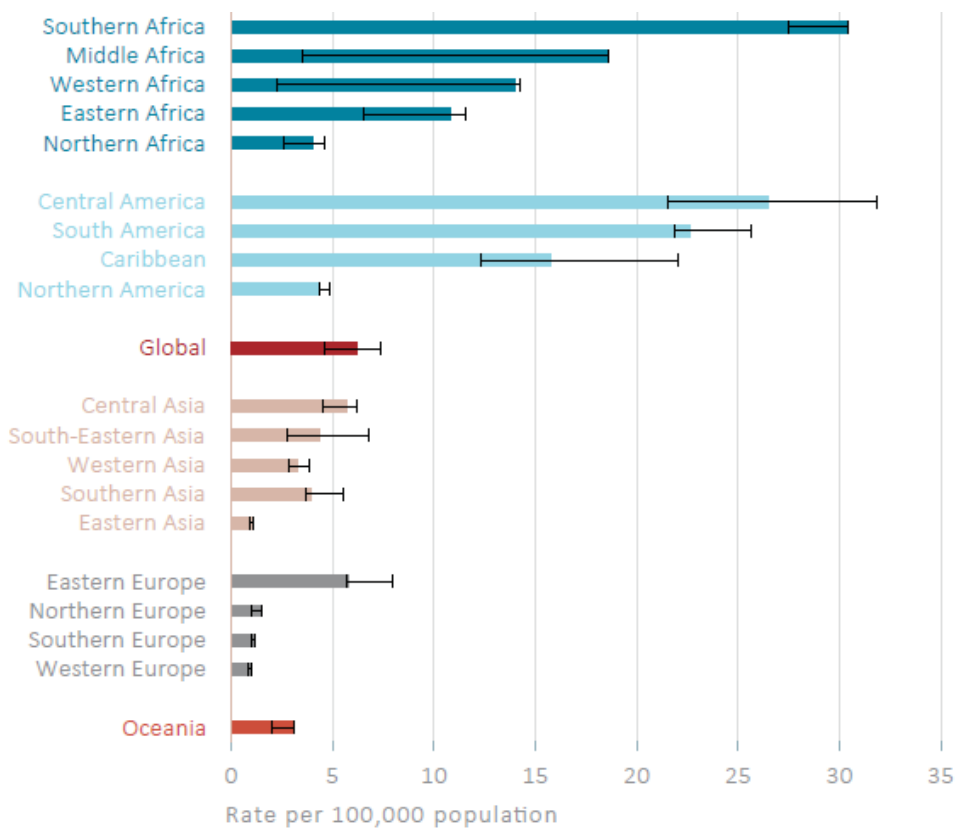

Fuente: UNODC. Global Study on Homicide.2013.

La desigualdad es el principal problema y desafío de América Latina y el Caribe. Las sociedades están fragmentadas por la alta inequidad. Esta es la región más inequitativa en términos comparativos del mundo, no la más pobre, la más desigual. La informalidad y el desempleo producen efectos de largo plazo. Uno de ellos son los "ni ni", jóvenes que no estudian ni trabajan.

Estudios de la OMS muestran una correlación entre inequidad y violencia. La movilidad social en la región es muy baja, sobre todo en lo referido a pueblos originarios y afro-descendientes. La exclusión y la "invisibilización" de estos incrementan las desigualdades. La polarización social genera una nueva configuración de incluidos / excluidos. Estas situaciones de alta desigualdad y de exclusión generan desafección ciudadana, desafección frente al estado de derecho y la democracia. 

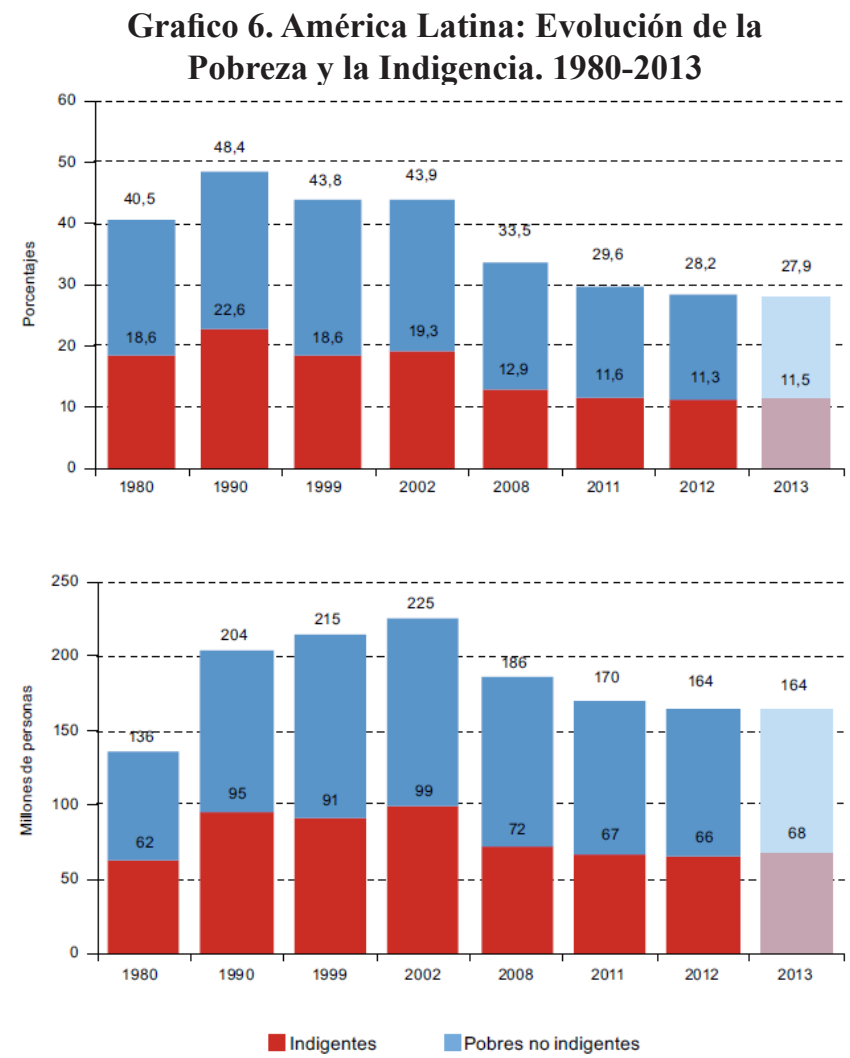

Fuente: CEPAL. (2013) Panorama Social de América Latina. Noviembre, 2013. En: www.eclac.org

Un problema asociado es el referido a la corrupción. En sociedades altamente desiguales, con baja movilidad social, se buscan "escapes", formas ilegítimas que permitan reconocimiento e inclusión. La corrupción corroe a nuestros sistemas políticos y crecientemente la mayoría de ellos posee un pobre desempeño en esta materia. 


\section{América Latina: Ranking de Índice de Percepción de la Corrupción}

\begin{tabular}{|c|c|c|c|}
\hline $\mathbf{1 - 3 3}$ & $\mathbf{3 4 - 7 9}$ & $\mathbf{8 0 - 1 3 0}$ & $\mathbf{1 3 1 - 1 7 9}$ \\
\hline Barbados (15) & Dominica (41) & Perú (83) & Guayana \\
Uruguay (19) & Costa Rica (49) & Trinidad y Tobago (83) & $(136)$ \\
Chile (22) & Cuba (63) & El Salvador (83) & Honduras \\
Santa Lucía & Brasil (72) & Jamaica (83) & $(140)$ \\
(22) & & Colombia (94) & Paraguay \\
San Vicente y & & Panamá (102) & $(150)$ \\
las Granadinas & & Ecuador (102) & Venezuela \\
$(33)$ & & México (106) & $(160)$ \\
& & Argentina (106) & Haití (163) \\
& & Bolivia (106) & \\
& & R. Dominicana (123) & \\
& & Guatemala (123) & \\
& & Nicaragua (127) & \\
\hline
\end{tabular}

Fuente: Transparencia Internacional 2013. En: www.tranparency.org

Una consecuencia directa es el aumento del consumo de drogas en la región. Por lo anterior, los vínculos entre desigualdad, violencia, corrupción generan oportunidades cada vez más amplias al crimen organizado trasnacional y a la generación de espacios sin ley, áreas en donde no hay monopolio estatal de la violencia, en todos los países de la región. No existen en ALyC “estados fallidos"15, pero sí zonas fallidas, áreas donde la autoridad legítima del Estado no llega, produciendo altos niveles de inseguridad, a la vez que se inhibe el desarrollo humano.

Los cambios globales y en particular los diseños de la política estadounidense han tendido a marcar de manera más profunda la heterogeneidad regional. $\mathrm{Si}$ bien América Latina constituye una macroregión, en ella se manifiestan dos regiones que se han fragmentado y que muestran tendencias diferenciadas en múltiples ámbitos. Un área norte de América Latina, liderada por México y en donde se incluyen los países de América Central, a la que pueden agregar los países del Caribe. Un área sur, constituida por los países que constituyen UNASUR, liderada por Brasil.

${ }^{15}$ En el índice de Estados Fallidos que publica Foreign Policy, sólo Haití se ubica en el lugar 7 y muestra tendencias que lo sacarán de los "top 10". Ningún otro país de ALyC aparece entre los 60 países más vulnerables en su estabilidad. 


\section{America latina: prácticas en materias de seguridad y defensa ${ }^{16}$}

\section{Una región de paz y un área desnuclearizada}

La II Cumbre de la CELAC (la Habana, 2014) declaró a la región como una zona de Paz. En ella se lee: "Nos comprometemos a seguir trabajando para consolidar a América Latina y el Caribe como Zona de Paz, en la cual las diferencias entre las naciones se resuelvan a través del diálogo y la negociación u otras formas de solución pacífica establecidas en el Derecho Internacional" 17 .

Los avances en las relaciones de seguridad y defensa en América Latina y el Caribe, en la década de los noventa, fueron el resultado de la resolución de los principales contenciosos fronterizos interestatales -Argentina-Chile, PerúEcuador, Salvador-Honduras y del fin de la competencia militar estratégica entre los principales actores; en especial la nuclear entre Argentina y Brasil. A ello se unió la resolución de contenciosos por parte de la Corte Internacional de Justicia.

El fin de la Guerra Fría permitió avanzar en la efectivización del Tratado sobre No Proliferación de Armas Nucleares, Tratado de Tlatelolco. Esto permitió hacer de la región un área libre de armas nucleares. Hacia mediados de 1997 los países de la región habían suscrito el tratado de no proliferación nuclear. Cabe señalar que la Zona Libre de Armas Nucleares de América Latina y el Caribe (ZLAN) se creó en $1967^{18}$, pero no fue hasta 2002, con la incorporación de Cuba, que se logró que los 33 Estados de América Latina y el Caribe formaran parte de la ZLAN. La región fue la primera área densamente poblada en el mundo que se declaró como Zona Libre de Armas Nucleares.

Los países latinoamericanos también son parte del Tratado sobre Prohibición Completa de Ensayos Nucleares, que fue abierto para firmar en 1996. Con la suscripción de este tratado se ratificó la voluntad regional de efectivizar una zona libre de armas nucleares. Los acuerdos y la cooperación han consolidado una situación de estabilidad interestatal amplia, posibilitando que la región se declare Zona de Paz y libre de armas nucleares.

Cabe destacar que los países de América Latina y El Caribe (con excepción de Cuba) son parte de la Convención de Ottawa ${ }^{19}$ sobre desminado y prohibición del uso de minas anti-personales. Esta Convención recibió una contundente y

${ }^{16}$ Algunas de estas ideas las desarrollé en Francisco Rojas Aravena. Seguridad Internacional, el Espacio y Posición de América Latina, en: Cuadernos de Estrategia, $N^{\circ} 158$, Los desafios de la seguridad en Iberoamérica. Instituto Español de Estudios Estratégicos. En: http://www.ieee.es/ Galerias/fichero/cuadernos/CE_158_DesafiosSeguridadIberoamerica.pdf

${ }^{17}$ CELAC. (2014) Declaración de la Habana. En: http://celac.cubaminrex.cu/sites/default/files/ ficheros/doc 3 1 declaracion_espanol 2.pdf

${ }_{18}$ Gioconda Ūbeda, Presentación Inicial de la Embajadora Gioconda Ubeda en el Foro del Organismo Internacional de Energía Atómica. 21 y 22 de noviembre de 2011. Viena.

${ }^{19}$ www.un.org/es/disarmament/instruments/convention landmines.shtml 
rápida respuesta por parte de los países de la región, quienes manifestaron su voluntad de proscribir la producción y uso de estas armas, y su compromiso con la limpieza de los campos minados existentes. En Centroamérica la OEA jugó un rol esencial en el proceso de desminado ${ }^{20}$.

La adecuada resolución de los temas referidos a la proliferación nuclear y al desarrollo de armas de destrucción masiva significa para América Latina una ventaja sustantiva frente a otras regiones. Esta ventaja comparativa se hace más evidente al observar la situación que aún enfrentan países como India y Pakistán, o las discusiones internacionales sobre la posibilidad de que Irán posea armas de destrucción masiva y su efecto desestabilizador para el Medio Oriente.

El trabajo del Organismo para la Proscripción de las Armas Nucleares en la América Latina y el Caribe (OPANAL) ha sido central para la consolidación de la ZLAN y los avances en materia de desarme nuclear y no proliferación. Asimismo, por medio de este organismo los países latinoamericanos promueven una importante lucha para que se logren iniciativas, como la de un instrumento universal jurídicamente vinculante que prohíba las armas nucleares, o la prohibición de los ensayos nucleares y con ello la adhesión universal al Tratado de Prohibición Completa de los Ensayos Nucleares ${ }^{21}$. En este sentido Latinoamérica es una asidua luchadora por la desnuclearización.

La importancia que le dan los países de la región a esta temática se refleja en el "Comunicado Especial sobre la Eliminación Total de las Armas Nucleares", que suscribieron los Estados latinoamericanos y caribeños en el marco de la I Cumbre de la CELAC en la que reiteran su compromiso con la importancia de lograr el desarme nuclear, completo y verificable. También "Afirmaron su deseo de que la CELAC articule una posición común ante las cuestiones del desarme nuclear, no proliferación y uso pacífico de la energía nuclear $(. . .)^{\text {"'22 }}$.

Sin embargo aún existen desafíos. De acuerdo a la ex Secretaria General de OPANAL, Gioconda Ubeda, algunos de los mayores desafíos son: a) si bien es cierto que la región es la única ZLAN que tiene firmados y ratificados los dos protocolos adicionales al Tratado de Tlatelolco por parte de todas las potencias que están vinculadas a ellos, lo cierto es que Estados Unidos, Reino Unido, Francia y Rusia realizaron algunas declaraciones interpretativas a los textos de estos protocolos que ponen en duda la consolidación de las garantías negativas de seguridad por parte de estos países. Este es un tema que se ha

\footnotetext{
${ }^{20}$ www.oas.org/es/temas/minas.asp

21 OPANAL. Declaración de los Estados Miembros del OPANAL. S/Inf.1071. México D. F. Septiembre.

22 Jefes y Jefas de Estado y de Gobierno de América Latina. Comunicado Especial sobre la Eliminación Total de las Armas Nucleares. I Cumbre de la Comunidad de Estados Latinoamericanos y caribeños. 2 y 3 de diciembre de 2011.
} 
venido negociando desde 2010; y b) un segundo gran desafío tiene relación con el desarrollo de la energía nuclear con fines pacíficos que "(...) plantea a la región nuevos desafíos en lo que respecta a garantizar el desarrollo, sin discriminación alguna, de esa energía para los países que lo requieran y al mismo tiempo garantizar que su uso solo será para fines civiles"23.

De igual forma la CELAC también destacó el rol de la Agencia BrasileñoArgentina de Contabilidad y Control de Materiales Nucleares (AABCN) ${ }^{24}$. Ésta corresponde a buenas experiencias y buenas prácticas de la región que permitirán ser aplicados en otras regiones.

\section{Contenciosos y mecanismos de resolución de conflictos en la región ${ }^{25}$}

Si bien es cierto que los conflictos no tradicionales son los que más gravitaron en los países de la región, los conflictos tradicionales aún mantienen su presencia. En efecto, existe una cantidad muy importante de contenciosos ligados al eje soberano territorial. En todas las subregiones latinoamericanas se detectan más de cuarenta contenciosos limítrofes con reivindicaciones territoriales y/o problemas de delimitación tanto marítima como terrestre. La diferencia radica actualmente en que en la resolución de este tipo de disputas ya no está la amenaza del uso de la fuerza, como sucedía todavía en las décadas de los ochenta y los noventa. En más de 25 oportunidades hubo demostraciones de uso de la fuerza por medio del despliegue militar efectivo y la disposición para usar la fuerza ${ }^{26}$. En el caso de Ecuador-Perú, en 1995, hubo una corta guerra, que requirió de una activa mediación internacional para detenerla. Ésta involucró por medio de la MOMEP (Misión de Observadores Militares Ecuador-Perú) a EE.UU., Argentina, Brasil y Chile. En la actualidad se ha pasado de una geopolítica autoreferente a una judicialización de los diferendos limítrofes. Los principales contenciosos históricos y los que han emergido en el siglo XXI han sido llevados a la Corte Internacional de La Haya.

No obstante lo anterior, siguen existiendo contenciosos y se sigue amenazando con la fuerza o la amenaza de ésta. En la "gran Colombia” el

\footnotetext{
${ }^{23}$ Gioconda Ubeda. La agenda regional para el desarme nuclear, en: Diálogo Político. Fundación Konrad Adenauer, 2010.

24 Jefes y Jefas de Estado de América Latina y el Caribe, Comunicado Especial sobre el Vigésimo Aniversario de la Agencia Brasileño-Argentina de Contabilidad y Control de Materiales Nucleares $(A A B C N)$. I Cumbre de la CELAC. 3 de diciembre de 2011. Caracas, Venezuela

${ }_{25}$ Francisco Rojas Aravena Francisco América Latina: Defensa y seguridad en el siglo XXI, en: Donadio, Marcela (compiladora). La reconstrucción de la seguridad nacional. Defensa, democracia y cuestión militar en América Latina. Buenos Aires: Prometeo Libros.

${ }^{26}$ David Mares, Conflictos limitrofes en el Hemisferio Occidental: Análisis de su relación con las estabilidad democrática, la integración económica y el bienestar social, en: Domínguez, Jorge (ed.). (2003) Conflictos territoriales y democracia en América Latina. Buenos Aires: Universidad de Belgrano/FLACSO- Chile/ editorial siglo XXI.
}

Araucaria. Revista Iberoamericana de Filosofia, Política y Humanidades, año 16, $\mathrm{n}^{\circ} 32$. Segundo semestre de 2014 Pp. 203-236. ISSN 1575-6823 e-ISSN 2340-2199 doi: 10.12795/araucaria.2014.i32.11 
uso y las amenazas del uso de la fuerza estuvieron presentes y fueron muy importantes entre los años 2008 y 2010. Primero entre Colombia y Ecuador, y luego entre Colombia y Venezuela. De la misma forma, en la parte sur de Centroamérica se produjo una invasión a un islote en el Río San Juan, que generó un conflicto internacional en el año 2014, que se mantiene todavía y que fue llevado a la OEA primero y a la Corte Internacional de Justicia después.

Las disputas territoriales o por recursos se mantienen con diferentes grados de intensidad entre algunas naciones ${ }^{27}$. De las diecisiete disputas entre los países de la región catorce tienen relación con temas territoriales y marítimos. Tres de ellos se ven exacerbados por los temas de explotación de recursos, tensiones migratorias y trasiegos ilegales de una frontera a otra. La Corte Internacional de Justicia ha resuelto sobre seis de estas disputas: Honduras-El Salvador; Honduras-Nicaragua; Costa Rica-Nicaragua (I), Argentina- Uruguay, Colombia-Nicaragua y Chile-Perú. También la Corte se encuentra resolviendo cinco contenciosos: Bolivia-Chile y dos casos diferentes entre Costa Rica y Nicaragua.

Otra serie de diferendos se encuentran latentes y no se han tomado medias para cerrarlos. En términos de disputas con países fuera de la región debe sumarse las disputas entre Argentina-Gran Bretaña; y Estados Unidos-Cuba.

\section{Gasto militar en la región}

En 2012 América Latina gastó 34.1 mil millones de dólares en armas y defensa, un aumento del $4.2 \%$ respecto de las cifras de 2011, de acuerdo con SIPRI $^{28}$. El gasto militar a nivel mundial disminuyó en 2012, con 1.7 billones de dólares, lo que representa el $2.5 \%$ del PIB global. En América Latina, el gasto en defensa fue de aproximadamente el $4 \%$ de su PIB total. El gasto total en defensa alcanzó los 4.3 mil millones de dólares en 2012, un aumento del $34 \%$ respecto de los 3.2 mil millones de dólares del 2011. La inversión anual en defensa de Brasil ha aumentado de 750 millones de dólares en 2004 a 4.3 mil millones en 2012, ubicándolo en el lugar 11 en gastos de defensa a nivel mundial y en primer lugar a nivel latinoamericano. La inversión en defensa de este país es el doble que la de Colombia, que tiene el segundo presupuesto más grande en América Latina, y 10 veces mayor que el de Argentina, de acuerdo con cifras del SIPRI.

\footnotetext{
${ }^{27}$ Gonzalo Álvarez y Claudio Fuentes, Statu Quo: Paradigmas tradicionales de seguridad en América Latina. Documento Preparado para la Reunión de RESDAL "La Situación de la Seguridad y la Defensa en América Latina". Bolivia. Julio, 2009.

${ }^{28}$ Instituto Internacional de Estocolmo para la Investigación de la Paz (SIPRI), SIPRI Yearbook 2013, Resumen en Español.
} 


\section{Gasto Militar Mundial 2012}

\begin{tabular}{|l|l|l|}
\hline Región & Gasto (\$b.) & Cambio (\%) \\
\hline África & 39.2 & 1.2 \\
\hline África del Norte & 16.4 & 7.8 \\
\hline África subsahariana & 22.7 & -3.2 \\
\hline América & 782 & -4.7 \\
\hline $\begin{array}{l}\text { América central y el } \\
\text { caribe }\end{array}$ & 8.6 & 8.1 \\
\hline Norte América & 708 & -5.5 \\
\hline Sur América & 65.9 & 3.8 \\
\hline Asia and Oceanía & 390 & 3.3 \\
\hline Asia central y sur & 59.8 & -1.6 \\
\hline Asia del este & 268 & 5.0 \\
\hline Oceanía & 28.2 & -3.7 \\
\hline Sur este asiático & 33.7 & 6.0 \\
\hline Europa & 407 & 2.0 \\
\hline Europa del este & 100 & 15 \\
\hline Europa del oeste & 307 & -1.6 \\
\hline Medio Oriente & 138 & 8.3 \\
\hline Total mundial & 1756 & -0.4 \\
\hline
\end{tabular}

Nota: Las cifras entre ( ) son estimaciones hechas por SIPRI Fuente: SIPRI. SIPRI Yearbook 2013. En: www.sipri.org

Este crecimiento no debe llevar a pensar necesariamente en un rearme de la región. Como hemos señalado, el presupuesto en defensa de los países latinoamericanos tradicionalmente tiende a destinarse mayoritariamente a los gastos de personal antes que a gastos operativos y reequipamiento militar. Generalmente, este gasto ronda al menos en un $70 \%$ del gasto militar de la región. Sin embargo, debe tenerse presente que los gastos en las adquisiciones de equipo muchas veces no están incluidos en los rubros de los presupuestos de defensa, sino en partidas diferentes de los presupuestos nacionales, como por ejemplo las de gastos en infraestructura ${ }^{29}$. El SIPRI señala además que un motivo más por el cual la región evidencia un crecimiento en gasto militar mayor a las otras regiones del mundo se debe a que América Latina no se vio tan afectada por la crisis financiera internacional como sí les ha ocurrido a otras, como Europa y América del Norte.

29 Carlos Malamud. ¿Rearme o renovación del equipamiento militar en América Latina?, en: Documento de Trabajo $N^{o}$ 31. "Real Instituto Elcano". 15 de diciembre, 2006. En: www. realinstitutoelcano.org 


\section{América Latina: Gasto Militar como \% del PIB}

\begin{tabular}{|c|c|c|c|c|c|c|c|c|c|}
\hline País & 2004 & 2005 & 2006 & 2007 & 2008 & 2009 & 2010 & 2011 & 2012 \\
\hline Argentina & 1.0 & 0.9 & 0.9 & 0.9 & 0.8 & 1.0 & 0,9 & 0,9 & 0,9 \\
\hline Bolivia & 2.0 & 1.9 & 1.7 & 1.8 & 2.0 & 2.0 & 1,7 & 1,5 & 1,5 \\
\hline Brasil & 1.5 & 1.5 & 1.5 & 1.5 & 1.5 & 1.6 & 1,6 & 1,5 & 1,5 \\
\hline Chile & 3.7 & 3.6 & 3.5 & 3.4 & 3.5 & 3.5 & 2,2 & 2,2 & 2,0 \\
\hline Colombia & 3.6 & 3.4 & 3.3 & 3.3 & 3.6 & 3.7 & 3,6 & 3,1 & 3,3 \\
\hline Costa Rica & - & - & - & - & - & - & - & - & - \\
\hline El Salvador & 0.7 & 0.6 & 0.6 & 0.6 & 0.5 & 0.7 & 1,1 & 1,1 & 1,0 \\
\hline Ecuador & 2.2 & 2.6 & 2.3 & 2.9 & 2.8 & 3.4 & 3,1 & 3,2 & 2,8 \\
\hline Guatemala & 0.4 & 0.4 & 0.4 & 0.4 & 0.4 & 0.4 & 0,4 & 0,4 & 0,4 \\
\hline Honduras & {$[0.8]$} & {$[0.8]$} & 0.7 & 0.9 & 1.5 & 1.5 & 1,1 & 1,1 & 1,1 \\
\hline México & 0.4 & 0.4 & 0.4 & 0.5 & 0.5 & 0.5 & 0,6 & 0,6 & 0,6 \\
\hline Nicaragua & 0.7 & 0.7 & 0.7 & 0.7 & 0.7 & 0.7 & 0,5 & 0,5 & 0,6 \\
\hline Panamá & - & - & - & - & - & - & - & - & - \\
\hline Paraguay & 0.9 & 0.8 & 0.8 & 0.8 & 0.8 & 0.9 & 1,1 & 1,2 & 1,7 \\
\hline Perú & 1.4 & 1.5 & 1.3 & 1.2 & 1.1 & 1.4 & 1,2 & 1,1 & 1,3 \\
\hline R. Dominicana & 0.7 & 0.8 & 0.7 & 0.7 & 0.7 & 0.7 & 0,7 & 0,6 & 0,6 \\
\hline Uruguay & 1.4 & 1.3 & 1.3 & 1.2 & 1.3 & 1.6 & 2,0 & 1,9 & 1,9 \\
\hline Venezuela & 1.3 & 1.4 & 1.6 & 1.3 & 1.4 & 1.3 & 0,9 & 0,8 & 1,1 \\
\hline
\end{tabular}

Fuente El Banco Mundial, Datos.

En: http://datos.bancomundial.org/indicador/MS.MIL.XPND.GD.ZS

Como se puede apreciar en el Cuadro anterior, el gasto militar de América Latina tiende a mantenerse estable, sin cambios bruscos o de gran impacto desde inicios del siglo XXI.

\section{América Latina en Organizaciones de Paz en la ONU}

El cambio originado con la emergencia del terrorismo de alcance global y la respuesta de carácter unilateral de los Estados Unidos cerró muchas de las oportunidades de cooperación para la paz que se abrieron en el período 1989-2011. En ese contexto de fuerte unilateralismo los costos negativos afloraron sin dificultad ${ }^{30}$.

Ello brindó otras oportunidades para ampliar la colaboración y cooperación entre los países latinoamericanos. Estas permitieron brindar respuestas conjuntas, como lo evidencia el caso haitiano. La MINUSTAH muestra cómo todos los temas de la interoperatividad y la acción conjunta de las fuerzas pueden ser resueltos en la práctica. También, no sin dificultades, registra grados de concertación y cooperación política decisivos en 2011. Es decir, la conducción política de la operación, a cargo de los Ministerios de la Defensa y de Relaciones Exteriores, de los 11 países participantes:

\footnotetext{
${ }^{30}$ Claudio Fuentes (ed), Bajo la Mirada del Halcón: Estados Unidos-América Latina post 11/9/2001, FLACSO Chile, Buenos Aires, 2004; Hernández, Jairo y Lizano, Ana Cristina. (editores) Op Cit. 
Argentina, Brasil, Chile, Ecuador, Bolivia, Guatemala, Honduras, Perú, Colombia, El Salvador, Uruguay. El 60\% de las tropas de la MINUSTAH son latinoamericanas ${ }^{31}$. De allí hay muchas lecciones que sacar, que aún no las hemos formulado ${ }^{32}$. Esta es una experiencia que muestra las potencialidades de cooperación militar, bajo liderazgo civil, y que refuerza los lazos en materias de defensa. Un reto particular sería cómo mejorar la coordinación en el ámbito subregional, entre los ministerios de la defensa de los países miembros de cada sub-esquema.

Si bien es cierto la MINUSTAH es la operación de paz donde se observa una mayor participación latinoamericana, los países de la región también colaboran en otras operaciones de las Naciones Unidas.

América Latina: Participación en Operaciones de Paz (abril 2014)

\begin{tabular}{|c|c|}
\hline Operación & Países involucrados \\
\hline $\begin{array}{l}\text { Misión de Asistencia de las } \\
\text { Naciones Unidas en la República } \\
\text { de Sudán del Sur (UNMISS) }\end{array}$ & $\begin{array}{l}\text { Brasil, El Salvador, Guatemala, } \\
\text { Paraguay, Perú, Ecuador, } \\
\text { Bolivia, Argentina }\end{array}$ \\
\hline $\begin{array}{l}\text { Fuerza Provisional de Seguridad de las } \\
\text { Naciones Unidas para Abyei (UNISFA) }\end{array}$ & Brasil, Ecuador, El Salvador, Bolivia \\
\hline $\begin{array}{l}\text { Misión de las Naciones Unidas } \\
\text { en la República Democrática } \\
\text { del Congo (MONUSCO) }\end{array}$ & $\begin{array}{l}\text { Bolivia, Guatemala, Paraguay, } \\
\text { Brasil, Perú, Uruguay }\end{array}$ \\
\hline $\begin{array}{c}\text { Operación Híbrida de la Unión } \\
\text { Africana y las Naciones Unidas } \\
\text { en Darfur (UNAMID) } \\
\end{array}$ & Bolivia, Ecuador, Perú \\
\hline $\begin{array}{l}\text { Operación de las Naciones Unidas } \\
\text { en Costa de Marfil (ONUCI) }\end{array}$ & $\begin{array}{l}\text { Bolivia, Brasil, Ecuador, } \\
\text { Guatemala, Paraguay, Perú, } \\
\text { Uruguay, Argentina, El Salvador }\end{array}$ \\
\hline $\begin{array}{l}\text { Misión de las Naciones Unidas } \\
\text { en Liberia (UNMIL) }\end{array}$ & $\begin{array}{l}\text { Bolivia, Brasil, Ecuador, Uruguay, } \\
\text { Paraguay, Perú, Argentina }\end{array}$ \\
\hline $\begin{array}{l}\text { Misión de las Naciones Unidas } \\
\text { para el referéndum del Sáhara } \\
\text { Occidental (MINURSO) }\end{array}$ & $\begin{array}{l}\text { Argentina, Brasil, El Salvador, } \\
\text { Honduras, Paraguay, Uruguay }\end{array}$ \\
\hline $\begin{array}{l}\text { Misión de Estabilización de las Naciones } \\
\text { Unidas en Haití (MINUSTAH) }\end{array}$ & $\begin{array}{c}\text { Argentina, Brasil, Chile, Ecuador, } \\
\text { Bolivia, Guatemala, Honduras, Perú, } \\
\text { Colombia, El Salvador, Uruguay }\end{array}$ \\
\hline $\begin{array}{c}\text { Grupo de Observadores Militares de las } \\
\text { Naciones Unidas en la India y } \\
\text { el Pakistán (UNMOGIP) }\end{array}$ & Chile, Uruguay \\
\hline $\begin{array}{c}\text { Fuerza de las Naciones Unidas } \\
\text { para el Mantenimiento de la } \\
\text { Paz en Chipre (UNFICYP) }\end{array}$ & Argentina, Brasil, Chile, \\
\hline
\end{tabular}

Fuente: ONU (2014), Operaciones de mantenimiento de la paz. En: www.un.org/es/peacekeeping

31 Entrevista Embajador de Argentina en Haití, Ernesto López. Noviembre, 2007.

32 Gabriel Aguilera, Las misiones militares. Pasado, presente y futuro. Documento Preparado para la Reunión de RESDAL “La Situación de la Seguridad y la Defensa en América Latina”. Bolivia. Julio, 2009 


\section{Nuevos organismos de concertación regional}

El instrumento más importante de coordinación hemisférica en los más distintos ámbitos y temas de seguridad sigue siendo la OEA; más allá de todas sus debilidades. La Secretaria de Seguridad Multidimensional de la OEA actualmente es la Secretaria Técnica de los Ministros de Seguridad Pública de las Américas, de la Conferencia de Ministros de Defensa; coordina la Junta Interamericana de Defensa; la Comisión Interamericana para el Control y Abuso de Drogas; el instrumento que es el mecanismo de evaluación multilateral; el Comité Interamericano contra el terrorismo; la Convención Interamericana contra la Fabricación Ilícita del Tráfico de Armas de Fuego, Municiones, Explosivos. Así también, el Plan Hemisférico contra la Delincuencia Organizada Transnacional; la Convención Interamericana sobre Transparencia y Adquisición de Armas Convencionales; al programa de asistencia integral en las minas antipersonales. Recientemente ha estado elaborando el Observatorio de las Tendencias del Crimen y la Violencia, es decir, sigue siendo el principal instrumento en el cual los países latinoamericanos, del Caribe, los Estados Unidos y Canadá entregan información y coordinan sus políticas. Sin embargo, la acción concertada muchas veces se ve debilitada por las dificultades operativas de ejecución.

El Tratado Interamericano de Asistencia Recíproca (TIAR) tiene vigencia legal pero tiene poca viabilidad y por lo tanto no hay un sistema regional de defensa, ni un pacto de seguridad regional. La Carta Democrática de las Américas es otro instrumento esencial, tiene 13 años. Ella incluye aspectos específicos respecto al rol de la vinculación civil militar en los sistemas democráticos.

Por su parte la Junta Interamericana de Defensa ${ }^{33}$ no ha tenido capacidad para renovarse de manera importante y significativa, con lo que pierde legitimidad en el nuevo contexto. El retiro de la mayoría de los países del ALBA le ha restado aun mayor viabilidad.

En el contexto hemisférico, con el fin de la Guerra Fría hubo un cambio drástico pasando de la desconfianza y la confrontación a la construcción de una nueva agenda hemisférica basada en la democracia, el libre mercado y la necesidad de fortalecer el multilateralismo en la región. Es así como surgen las Cumbres de las Américas, cuya primera reunión se realizó del 9 al 11 de diciembre de 1994 en Miami, con el objetivo de reorganizar las relaciones entre los países del continente adecuando las discusiones a las nuevas condiciones regionales y mundiales. Esta instancia se debilitó profundamente en 2005 y las dos últimas reuniones han culminado sin una declaración y con diferencias importantes sobre los participantes y el rol del mecanismo.

\footnotetext{
${ }^{33}$ Sobre esto ver John A. Cope, Reforming the Inter-American Defense Board. Strategic Forum. National Defense University. Octubre, 2010.
}

Araucaria. Revista Iberoamericana de Filosofía, Política y Humanidades, año 16, $\mathrm{n}^{\circ} 32$. Segundo semestre de 2014. Pp. 203-236. ISSN 1575-6823 e-ISSN 2340-2199 doi: 10.12795/araucaria.2014.i32.11 


\section{Las Conferencias Ministeriales de Defensa}

Es en dicho contexto histórico donde surge y se concretiza la idea de realizar una reunión de Ministros de Defensa de las Américas como un mecanismo que facilitara el propósito de organizar y vincular de forma efectiva democracia, desarrollo económico y seguridad internacional por parte de los actores del hemisferio.

Otros elementos que tuvieron un peso precipitador de estas reuniones fueron las crisis generadas por el conflicto entre Ecuador y Perú, la crisis política en Haití y el tema migratorio, entre otros. A estos factores se les deben sumar las amenazas emergentes en la región, como el potencial peligro en la proliferación de armas, el tráfico internacional de drogas, los temas ambientales y los relacionados con el vínculo civil-militar y su impacto sobre los derechos humanos y la democracia ${ }^{34}$. Los días 24 al 26 de julio de 1995 se realizó en Williamsburg, Virginia, la I Conferencia de Ministros de Defensa de las Américas, constituyéndose en la primera reunión de este tipo del Hemisferio Occidental, y cuya promesa fue: "Ningún Estado por sí solo podrá tener éxito, unidos no podremos fallar. Esa es la promesa de la asociación que hoy día tienen los líderes de las Américas" ${ }^{35}$. Las ministeriales de defensa se han sucedido desde esa fecha.

La última Conferencia Ministerial de Defensa realizada se llevó a cabo en octubre de 2011 en Uruguay. La siguiente también se realizará en el mes de octubre en Perú. En las diversas oportunidades los ministros han expresado la importancia de preservar los principios de Williamsburg, promover los procesos de modernización en defensa, reconocer la importancia de la cooperación en defensa, particularmente respecto de los avances que se han logrado en medidas de confianza mutua, y recomendaron el intercambio de criterios entre las nociones de defensa y seguridad para delimitar los ámbitos de cada una.

\section{Las Reuniones de Ministros de Seguridad Pública}

En el contexto de la cooperación hemisférica promovida por la OEA se encuentran también las reuniones de Ministros de Seguridad Pública. Si bien es cierto en 2003 la Declaración de Seguridad de las Américas mostró las nuevas amenazas, las amenazas no tradicionales en el hemisferio, fue necesario que pasaran 5 años antes de que hubiera una acción efectiva y se desarrollase la primera reunión de Ministros de Seguridad Pública de las Américas (MISPA) en México (2008); al año siguiente, 2009, se realizó la segunda en república

\footnotetext{
${ }^{34}$ Francisco Rojas Aravena "Williamsburg: ¿Un giro definitivo en las relaciones hemisféricas de seguridad?” En: Revista Ser en el 2000. Argentina, 1995. En: www.ser2000.org.ar

35 Ibid.
} 
Dominicana; en noviembre de 2011 tuvo lugar la tercera reunión de Ministros de Seguridad Pública en las Américas, en Puerto España (Trinidad y Tobago) y en el año 2013 en Colombia ${ }^{36}$.

En el ámbito Iberoamericano se ha reconocido la importancia de mejorar la seguridad. Los mandatarios de los países Iberoamericanos suscribieron, en la XXI Cumbre Iberoamericana celebrada en Asunción, en octubre de 2011, el "Comunicado Especial sobre Seguridad Ciudadana y Seguridad Pública", en el que manifiestan, entre otros, "El compromiso de promover una mayor participación y cooperación entre los Estados, la ciudadanía, los organismos internacionales, la sociedad civil para consolidar el intercambio de conocimientos, de experiencias y de buenas prácticas, conforme a los nuevos paradigmas de la Seguridad Pública" ${ }^{37}$.

\section{El Consejo de Defensa Suramericano}

En el caso de América del Sur, en el marco de la UNASUR se han creado dos consejos importantes de destacar. Por un lado, en términos de cooperación en defensa, se encuentra el Consejo de Defensa Sudamericano (CDS), cuyo objetivo es ser una instancia de consulta, cooperación y coordinación en materia de Defensa en dicha región.

A inicios de 2008 el Ministro de Defensa de Brasil, Nelson Jobim, realizó una gira por los países miembros de la Unión de Naciones Suramericanas para promover la iniciativa brasileña de crear un Consejo de Defensa Suramericano, que se constituiría en un mecanismo de integración que permitiera discutir las realidades y necesidades de defensa de los países sudamericanos, reducir los conflictos y desconfianzas y sentar las bases para la futura formulación de una política común en dicha área ${ }^{38}$. Sin embargo, debido a las tensiones entre algunos países de la región, en especial entre Colombia y Ecuador debido a la incursión militar colombiana en territorio ecuatoriano para atacar un campamento de las FARC, no fue hasta el 16 de diciembre de 2008, en una Cumbre Extraordinaria de UNASUR, que los Jefes y Jefas de Estado sudamericanos aprobaron la creación del Consejo de Defensa Suramericano definido como una "instancia de consulta, cooperación y coordinación en materia de Defensa en armonía con las disposiciones del Tratado Constitutivo de UNASUR". Este Consejo está regido por los principios y propósitos establecidos en la Carta de las Naciones Unidas y en las Cartas de la OEA, así como en los mandatos y decisiones del Consejo de Jefes y Jefas de Estado y de Gobierno de la UNASUR ${ }^{39}$.

\footnotetext{
${ }^{36}$ http://www.oas.org/dsp/espanol/cpo mispa4 preparatoria.asp

37 Jefes y Jefas de Estado y de Gobierno de los Países Iberoamericanos. (2011) Comunicado Especial sobre Seguridad Ciudadana y Seguridad Pública. XXI Cumbre Iberoamericana. Asunción, Paraguay. Octubre.

38 "Presidentes de UNASUR crean grupo de trabajo para definir Consejo de Defensa", en: Artículos Periodísticos. 23 de mayo, 2008. En: www.comunidadandina/sudamerica.htm

${ }^{39}$ Jefes y Jefas de Estado de UNASUR. (2008) Cumbre Extraordinaria de UNASUR. Decisão Para
} 
La creación del Consejo de Defensa Suramericano es otra muestra del liderazgo que ocupa Brasil en la región, más aún si se toma en cuenta que en 2003 el presidente de Venezuela, Hugo Chávez, había propuesto crear una Organización del Tratado del Atlántico Sur (OTAS), una especie de OTAN suramericana que no prosperó. Asimismo, este Consejo refleja la apuesta de Brasil por un sistema colectivo de defensa y por sub-regionalizar la cooperación militar ante un escaso y limitado nivel de cooperación hemisférica ${ }^{40}$. Los cuatro ejes del CDS son: Política de Defensa, Cooperación Militar y Acciones Humanitarias, Industria y Tecnología de la Defensa, y Formación y Capacitación. Asimismo en mayo de 2011 se inauguró en Buenos Aires el Centro de Estudios Estratégicos de la Defensa (CEED), institución adscrita al CDS y que busca ser un centro permanente de investigación académica sobre seguridad y defensa. Un paso importante de destacar de la acción del CDS es su trabajo en la elaboración de una Metodología Común para la Medición de Gastos en Defensa de sus países miembros ${ }^{41}$. Desde el año 2013, se ha trabajado en el desarrollo de una Escuela Suramericana de Defensa.

Por otro lado, el 4 de mayo de 2010 se creó el Consejo Suramericano sobre el Problema Mundial de las Drogas que es una Instancia permanente de la UNASUR de consulta, cooperación y coordinación para enfrentar el problema mundial de las drogas.

\section{La Cooperación en Centroamérica}

A nivel latinoamericano, la cooperación en defensa entre los países de la región frente a las nuevas y viejas amenazas aún es muy débil. En términos generales se pueden nombrar algunas grandes alianzas. En el Norte de América Latina se observan los esfuerzos liderados y/o apoyados por México y Estados Unidos, que hasta 2011 se regían principalmente por la Iniciativa Mérida, de carácter bilateral, y que como se dijo anteriormente tiene una visión muy punitiva y militarizada del problema de la inseguridad y de las drogas.

Fue hasta el año 2011 donde se observó el cambio de giro en la política de seguridad de esta subregión con la Conferencia Internacional de Apoyo a la Estrategia de Seguridad realizada en Guatemala, en junio de 2011. En esta Conferencia se discutió y presentó la Estrategia de Seguridad concordada en el Sistema de Integración Centroamericana (SICA ${ }^{42}$. Se trata de una estrategia construida por la subregión, y que busca tener una proyección regional. Asimismo

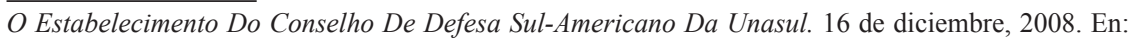
www.defensa.gov.br

40 Susanne Gratius, ¿Hacia una OTAN Sudamericana? Brasil y un Consejo de Defensa Sudamericano, en: "FRIDE". 10 de abril, 2008. En: www.fride.org

${ }^{41}$ Ministros de Defensa de Suramérica. (2011) Declaración de Lima. III Reunión Ordinaria del Consejo de Defensa Suramericano. 12 y 13 de mayo de 2011. Lima, Perú.

${ }^{42}$ SG SICA. (2011) Estrategia de Seguridad de Centroamérica. Junio. 
resulta fundamental en un contexto donde para el año 2006 se calcula que la violencia tuvo un costo de alrededor de 6.505,9 millones de dólares, lo que sería el equivalente al 7,7\% del PIB regional ${ }^{43}$. Es decir, se trata de una estrategia que se le presenta a Estados Unidos y otros socios de la región, y no una impuesta por ellos. La convocatoria de la Conferencia fue un éxito, pues además de los presidentes de Centroamérica, Colombia y México asistió la Secretaria de Estado de los Estados Unidos, Hillary Clinton, los Cancilleres de España y Chile y más de 50 delegaciones de organismos internacionales y 60 países.

La Estrategia tiene 4 componentes: a) Combate al delito; b) Prevención de la violencia; c) Rehabilitación, reinserción y seguridad penitenciaria; y d) Fortalecimiento institucional. Para Pedro Caldentey ${ }^{44}$ el mayor éxito de la Conferencia fue el reconocimiento explícito del problema de seguridad de la subregión como uno de responsabilidad compartida. Este autor destaca la formulación de cuatro principios que pueden desprenderse de la Declaración Final: a) el principio de corresponsabilidad de la comunidad internacional; b) el principio de regionalidad, que implica que los países deberán tomar medidas regionales además de los esfuerzos que puedan hacer a nivel interno; c) el principio de apropiación de la Estrategia por parte de los países centroamericanos; y, d) el principio de adicionalidad de los recursos obtenidos a los presupuestos nacionales y proyectos de cooperación.

Cabe señalar que la Estrategia ha sido apoyada por el resto de los países de América Latina y el Caribe. Así quedó plasmado en el "Comunicado Especial sobre el Respaldo a la Estrategia de Seguridad de Centroamérica", suscrito por los mandatarios y mandatarias de la región en la I Cumbre de la CELAC ${ }^{45}$.

En lo que respecta a la defensa, en el caso centroamericano existe la Conferencia de las Fuerzas Armadas de Centroamérica (CFAC) creada desde 1997 por los Gobiernos de Guatemala, El Salvador, Honduras y Nicaragua, y que incluye actividades como el Plan de la CFAC de cooperación integral para prevenir y contrarrestar el terrorismo, crimen organizado y actividades conexas. Entre estas: Unidad Humanitaria y de Rescate de la CFAC (UHR-CFAC); Programa anual de medidas de fomento de la confianza de carácter militar; intercambios de Oficiales en el Área Educativa entre las Fuerzas Armadas y Ejércitos; desarrollo de convenios de cooperación y actividades conjuntas con la Corte Centroamericana de Justicia, Comité Internacional de la Cruz Roja,

${ }^{43}$ Hugo Noé Pino, Gasto público en seguridad y justicia en Centroamérica, en Serie Estudios y Perspectivas. CEPAL. No132. México, D. F. Octubre de 2011.

${ }^{44}$ Pedro Caldentey, La Conferencia Internacional de Apoyo a la Estrategia de Seguridad: Un Upgrade a la Integración Centroamericana. Ponencia presentada en el Seminario "Multilateralismo y nuevas formas de integración en el América Latina en el contexto global”, realizado en San José, Costa Rica los días 4 y 5 de julio de 2011. Publicación en prensa

${ }^{45}$ Jefes y Jefas de Estado y de Gobierno de América Latina. Comunicado Especial sobre el Respaldo a la Estrategia de Seguridad de Centroamérica. I Cumbre de la Comunidad de Estados Latinoamericanos y caribeños. 2 y 3 de diciembre de 2011 
Iniciativa de Derechos Humanos, Organización de las Naciones Unidas para la Educación y la Cultura (UNESCO) y una comunicación permanente con la Secretaria General del SICA, Conferencia de Ejércitos Americanos, Junta Interamericana de Defensa, entre otros ${ }^{46}$.

\section{Propuestas desde el ALBA}

Otro proyecto de concertación e integración en materia de defensa es el que podría ser impulsado por los países de la Alianza Bolivariana de las Américas (ALBA). La cooperación en materia de defensa entre los países del ALBA se ha centrado en el discurso de preparase y protegerse frente a una amenaza externa, materializada principalmente en una posible invasión estadounidense. A nivel bilateral Venezuela ha impulsado su ayuda militar a los países miembros del ALBA mediante la firma de convenios de cooperación y recursos económicos.

Sin embargo, no fue hasta enero de 2008 cuando el presidente Chávez expresó su intención de crear un Consejo de Defensa Militar del ALBA, y acusó a Estados Unidos de utilizar a Colombia para ir contra los países del ALBA y Venezuela. El mandatario venezolano señaló que los países del ALBA debían trabajar para conformar una estrategia de defensa conjunta e ir articulando las Fuerzas Armadas, aéreas, Ejército, Marina, Guardia Nacional, las fuerzas de cooperación, y los cuerpos de inteligencia, pues el enemigo era el mismo: Estados Unidos ${ }^{47}$. Por su parte, el presidente de Nicaragua, Daniel Ortega, quien se encontraba de visita en Caracas, manifestó: "El que se meta con uno de nosotros tendrá que meterse con todos, porque actuaremos como uno solo"48. En la VII Cumbre Presidencial del ALBA, realizada el 17 de octubre de 2009, el presidente Chávez planteó la propuesta de firmar una alianza militar; empero los mandatarios de los países miembros del mecanismo expresaron que una decisión en este sentido requería de mayor discusión y análisis, por lo que acordaron crear un Comité Permanente de Soberanía y Defensa, instancia que tendrá la tarea de definir una "estrategia de defensa integral popular conjunta"49.

El tema de una alianza militar perdió fuerza desde entonces y solo en la XI Cumbre del ALBA vuelve a adquirir importancia tras la propuesta del presidente boliviano, Evo Morales, de estudiar la idea de conformar un Consejo de Defensa del ALBA ${ }^{50}$.

\footnotetext{
${ }^{46}$ www.ejercito.mil.ni/rmi cfac.html

47 "Chávez propone crear Consejo de Defensa Militar del ALBA ante agresiones extranjeras", en: $A B N .28$ de enero, 2008. En: www.alternativabolivariana.org

48 “Tocar a Venezuela es Incendiar la Región” Declaraciones de Daniel Ortega. 28 de enero, 2008. En: www.alternativabolivariana.org

49 "Países del ALBA acuerdan crear una "alianza militar y defensiva", en: El Universal. Venezuela. 18 octubre, 2009.

50 "Un Consejo de Defensa Propio es parte de la Iniciativa del ALBA", en: Ministerio del Poder Popular para Relaciones Exteriores. 5 de febrero de 2012,
} 
La muerte del Pte. Chávez cambió de manera drástica las posibilidades de impulsar y operativizar las ideas en diferentes campos. A ello se debe agregar el impacto de la crisis económica en Venezuela, lo que afecta la disponibilidad de recursos para la cooperación internacional dentro de los países del ALBA y de los asociados a Petrocaribe.

\section{Cooperación en el Caribe}

En julio de 2006 los Jefes de Estado y de Gobierno de los países miembros de CARICOM establecieron la Agencia de Implementación para el Crimen y la Seguridad (IMPACS por sus siglas en inglés) para servir de instrumento de aplicación de la nueva arquitectura regional para el desarrollo y manejo de la Agenda de Acción Regional en los temas de Seguridad y Delito de la Comunidad del Caribe. IMPACS tiene a su cargo dos sub agencias: el Centro Regional de Comunicaciones Conjuntas y el centro Regional de Fusión de la Inteligencia, ambos creados inicialmente como parte de la estrategia de seguridad implementada para el Mundial de Cricket realizado en los países caribeños en 2007, y que más adelante se tomó la decisión de establecer como permanentes.

\section{Algunas tendencias y proyecciones}

La seguridad y la defensa deben ser entendidas en su contexto sociohistórico-cultural-geográfico. El proceso de transformaciones globales ha obligado a cambiar los paradigmas con los cuales se piensan las relaciones de poder a nivel global y sus impactos a nivel nacional y local. Uno de los principales problemas tiene que ver con que el conocimiento se encuentra segmentado, hay una carencia de visiones integrales capaces de incorporar la multidimensionalidad de los fenómenos en perspectivas globales. Sin nuevos mapas conceptuales no podremos desarrollar un plan de acción capaz de enfrentar los grandes problemas en el sistema internacional y en los ámbitos locales.

En los temas de seguridad y defensa, las tendencias internacionales $\mathrm{y}$ regionales apuntaron hacia un mayor control y desactivación de los posibles conflictos a través de la acción multilateral, expresada en acuerdos, compromisos, declaraciones y la concertación de acciones. A mediados de la década de los 90s señalábamos que si "lo multilateral se impone como tendencia, en la resolución de los conflictos, la cooperación tendrá el mayor espacio y los dividendos para la paz serán más profundos" ${ }^{21}$.

\footnotetext{
${ }^{51}$ Francisco Rojas Aravena, América Latina en la posguerra fría: nuevas oportunidades para la cooperación para la paz, en: "Relaciones Internacionales", $\mathrm{N}^{\circ}$ 41, cuarto trimestre. Costa Rica, 1992. págs. 21 - 26
} 
América Latina, en el período de guerra fría, fue percibida y se autopercibió en un marco conceptual definido por el conflicto bipolar. La principal amenaza era el enemigo extra-continental. Con esto se reafirmaban tendencias previas provenientes del período anterior a la Segunda Guerra Mundial. En la actualidad se aprecia una transición conceptual, desde la perspectiva de guerra fría, hacia otra de posguerra fría. En ésta las amenazas son difusas y en ellas el peso de los factores militares se ha reducido. El fin del conflicto bipolar abrió una oportunidad para establecer una agenda de cooperación entre los países latinoamericanos y entre la región y Estados Unidos. Este cambio no fue sólo producto de un cambio en el balance de poder a nivel internacional (de una estructura bipolar a una unipolar de finales de siglo y a una de mayor peso multilateral), sino que estuvo fuertemente ligado a temas doméstico-regionales.

A nivel político, el retorno y la consolidación de los sistemas democráticos juega un rol decisivo a la hora de las nuevas conceptualizaciones de seguridad en el hemisferio. En las Américas, la institucionalidad democrática se ha expresado como "paz democrática", y ésta posee una fuerza sustantiva capaz de limitar y reducir los conflictos. En esta perspectiva, las cláusulas democráticas, asociadas a acuerdos políticos y comerciales, han jugado un rol central. Está surgiendo un nuevo derecho internacional referido a la democracia. De un compromiso moral se ha pasado a una norma vinculante en el contexto de la OEA, el MERCOSUR, el SICA y otras agrupaciones regionales.

En definitiva, el fin de la guerra fría, sumado a los cambios intra-regionales, produjo una revaluación de las principales matrices teóricas con las que se evalúan los fenómenos internacionales, así como las relaciones entre los Estados latinoamericanos. Esto permitió avanzar hacia la conformación de un nuevo marco conceptual en el cual, reconociendo el conflicto y la confrontación, es posible poner un mayor énfasis en la cooperación y promover la asociación. El concepto se seguridad cooperativa surge en este contexto y fue de particular importancia para la agenda de seguridad en América Latina y el Caribe desde principios de los 1990s.

La seguridad cooperativa consiste en la actuación anticipada sobre los conflictos a través del establecimiento de mecanismos diplomáticos y militares a nivel bilateral o multilateral para limitar o neutralizar dichos conflictos, disminuyendo así las posibilidades de su escalada ${ }^{52}$. Específicamente, es posible indicar que el concepto de seguridad cooperativa gira en torno a la "búsqueda de mecanismos que reduzcan las posibilidades y el alcance de las agresiones internacionales a través de la asociación preventiva de los Estados participantes para proteger su seguridad conjunta"s3.

\footnotetext{
52 Juan Rial, Un sistema regional cooperativo en el Cono Sur. Ponencia 20 años de política exterior en democracia, Octubre. 2003.

${ }^{53}$ Para más antecedentes sobre el concepto de seguridad cooperativa y su aplicación en el ámbito internacional ver: Nolan, Janne E. editor, "Global engagement: cooperation and security in the 21 st century", The Brookings Institution, Washington DC., 1994.
} 
Elementos esenciales en la seguridad cooperativa son la confianza y la transparencia de compromisos que asumen voluntariamente los estados, que implican ceder autonomía en función de objetivos comunes en materia de seguridad. Este proceso no es automático y se logra en forma gradual, a través de un período de negociaciones y de interacciones que generan rutinas, acuerdos y tratados; que muestran un cambio en la forma en que los actores perciben su propia práctica política y la de sus vecinos. El fortalecimiento de las instituciones democráticas, la profundización de la integración regional y una ampliación de las medidas de confianza y seguridad son los elementos necesarios para que esta estrategia de seguridad cooperativa se desarrolle.

El concepto de seguridad cooperativa es abordado por la Comisión especial sobre seguridad hemisférica de la OEA en 1993, destacando tres elementos centrales de este concepto: i) La necesidad de que hubiera entre los países de la región valores e intereses compartidos. ii) La identificación de aquellas situaciones que puedan atentar contra dichos valores y, simultáneamente, los diseños de mecanismos de prevención y reacción adecuados. iii) La consecución de los acuerdos necesarios sobre las medidas de acción colectiva tendiente a prevenir y, en su caso, neutralizar estas situaciones de riesgo ${ }^{54}$.

La seguridad cooperativa concebida en términos conceptuales plantea la búsqueda de fórmulas de consulta en vez de confrontación, seguridad y confianza en lugar de disuasión, transparencia en vez de ocultamiento, prevención en vez de corrección, e interdependencia en vez de unilateralismo ${ }^{55}$.

En la práctica es posible observar que desde inicios de los noventa se han producido cambios de gran estrategia en los Estados de la región, los cuales han reorientado las políticas públicas y las estrategias de los gobiernos de la subregión hacia relaciones crecientemente cooperativas, especialmente en el ámbito político, económico, socialy de seguridad, mediante una institucionalidad basada en la coordinación y concertación política intergubernamental.

Podemos observar una serie de ejemplos de seguridad cooperativa entre las que cabe mencionar la resolución de conflictos fronterizos, acuerdos de desarme especialmente de control relativos de armas atómicas, biológicas y químicas, mayor cooperación entre las fuerzas armadas, publicación de libros blancos por parte de los Ministerios de Defensa, entre otros temas. Sin embargo, la mayoría de estas iniciativas ha tenido lugar en el plano bilateral o iniciativas dentro de países de UNASUR. Un régimen de seguridad cooperativa (normas, reglas, instituciones comunes) que integren tanto a Sudamérica como a Centroamérica parece un objetivo mucho más elusivo.

\footnotetext{
54 Juan Rial, Ibid.

${ }^{55}$ Gareth Evans, "Cooperative Security and Intrastate Confict”, en Foreign Policy, No96. Otoño, 1994. pág.7
} 
En breve, el concepto de seguridad cooperativa es concebido esencialmente para generar estrategias de prevención de conflictos entre estados. Las nuevas amenazas a la seguridad -que son la preocupación central de la mayoría de los Estados latinoamericanos en la actualidad-, como el crimen organizado o el narcotráfico, no son concebidas dentro de este esquema. Tampoco lo son temas globales de seguridad como las pandemias, la crisis alimentaria, la energética o el cambio climático. Las estrategias propuestas dentro de la seguridad cooperativa, según indica Jorge Domínguez, como las Medidas de Confianza Mutua o la trasparencia del gasto militar, no parecen ser útiles para responder a los nuevos problemas de seguridad. En este sentido, es necesario repensar la seguridad cooperativa en el marco de los nuevos desafíos predominantes en la región. En este contexto las experiencias latinoamericanas son importantes en relación a otras regiones del mundo. Además sirven de base para repensar los desafíos a la seguridad y la defensa de la región desde la cooperación, la asociación y los proyectos de integración. 


\section{Referencias bibliográficas}

Aguilera, Gabriel (2009). Las misiones militares. Pasado, presente y futuro. Documento Preparado para la Reunión de RESDAL. "La Situación de la Seguridad y la Defensa en América Latina". Bolivia. Julio.

Álvarez, Gonzalo y Fuentes, Claudio (2009). Statu Quo: Paradigmas tradicionales de seguridad en América Latina. Documento Preparado para la Reunión de RESDAL "La Situación de la Seguridad y la Defensa en América Latina”. Bolivia. Julio.

Banco Mundial (2011). Crimen y Violencia en Centroamérica. Un Desafio para el Desarrollo. Documento del Banco Mundial, pp. 40. En: www. bancomundial.org

Beck, Ulrich (2008). La sociedad del riesgo mundial. En busca de la seguridad perdida. Ed. Paidos, Buenos Aires, pp. 334.

Caldentey, Pedro (2011). La Conferencia Internacional de Apoyo a la Estrategia de Seguridad: Un Upgrade a la Integración Centroamericana. Ponencia presentada en el Seminario "Multilateralismo y nuevas formas de integración en el América Latina en el contexto global", realizado en San José, Costa Rica los días 4 y 5 de julio de 2011. Publicación en prensa

CELAC (2014). Declaración de la Habana. En: http://celac.cubaminrex.cu/ sites/default/files/ficheros/doc_3_1_declaracion_espanol_2.pdf

CEPAL. Balance Preliminar de la Economía de América Latina y el Caribe. ONU / CEPAL. Santiago, Chile.

Chávez propone crear Consejo de Defensa Militar del ALBA ante agresiones extranjeras", en: $A B N$. 28 de enero, 2008. En: www.alternativabolivariana.org Cope, John A (2010). Reforming the Inter-American Defense Board. Strategic Forum. National Defense University. Octubre.

Evans, Gareth (1994). "Cooperative Security and Intrastate Confict", en Foreign Policy, №66. Otoño.

Foreign Policy .Índice de Estados Fallidos. En: http://www.foreignpolicy.com/ failedstates

Fuentes, Claudio (editor) (2004). Bajo la Mirada del Halcón: Estados UnidosAmérica Latina post 11/9/2001, FLACSO Chile, Buenos Aires.

Gratius, Susanne (2008). "Hacia una OTAN Sudamericana? Brasil y un Consejo de Defensa Sudamericano", en: FRIDE. 10 de abril. En: www.fride.org

II Foro sobre Medidas de Fomento de la Confianza y de la Seguridad. Actualización del Inventario de las Medidas de Fomento de la Confianza y la Seguridad (MFCS) (Informe presentado por la Junta Interamericana de Defensa). 31 de octubre, 2006. En: www.oas.org

Human Security Report Project, Human Security Report 2013. En: http://www. hsrgroup.org/human-security-reports/2013/text.aspx 
Instituto Internacional de Estocolmo para la Investigación de la Paz (SIPRI), SIPRI Yearbook 2013, Resumen en Español. En: http://www.sipri.org/ yearbook/2013/2013/files/sipri-yearbook-2013-resumen-en-espanol

Jefes y Jefas de Estado de América Latina y el Caribe (2011). Comunicado Especial sobre el Vigésimo Aniversario de la Agencia Brasileño-Argentina de Contabilidad y Control de Materiales Nucleares (AABCN). I Cumbre de la CELAC. 3 de diciembre de 2011. Caracas, Venezuela

Jefes y Jefas de Estado de UNASUR (2008). Cumbre Extraordinaria de UNASUR. Decisão Para O Estabelecimento Do Conselho De Defesa SulAmericano Da Unasul. 16 de diciembre, 2008. En: www.defensa.gov.br

Jefes y Jefas de Estado y de Gobierno de América Latina. Comunicado Especial sobre la Eliminación Total de las Armas Nucleares. I Cumbre de la Comunidad de Estados Latinoamericanos y caribeños. 2 y 3 de diciembre de 2011.

Jefes y Jefas de Estado y de Gobierno de América Latina. Comunicado Especial sobre el Respaldo a la Estrategia de Seguridad de Centroamérica. I Cumbre de la Comunidad de Estados Latinoamericanos y caribeños. 2 y 3 de diciembre de 2011.

Jefes y Jefas de Estado y de Gobierno de los Países Iberoamericanos. (2011) Comunicado Especial sobre Seguridad Ciudadana y Seguridad Pública. XXI Cumbre Iberoamericana. Asunción, Paraguay. Octubre.

Malamud, Carlos (2006). “¿Rearme o renovación del equipamiento militar en América Latina?", en: Documento de Trabajo $N^{\circ} 31$. Real Instituto Elcano. En: www.realinstitutoelcano.org

Mares, David (2003). "Conflictos limítrofes en el Hemisferio Occidental: Análisis de su relación con las estabilidad democrática, la integración económica y el bienestar social”, en: Domínguez, Jorge (editor). (2003) Conflictos territoriales y democracia en América Latina. Buenos Aires: Universidad de Belgrano/FLACSO- Chile/ editorial siglo XXI.

Mathieu, Hans y Rodríguez, Paula (editores) (2009). Anuario 2009 de la Seguridad regional en América Latina y el Caribe. Friedrich Ebert Stiftung. Colombia. En: www.ejercito.mil.ni/rmi cfac.html

Ministros de Defensa de Suramérica (2011). Declaración de Lima. III Reunión Ordinaria del Consejo de Defensa Suramericano. 12 y 13 de mayo de 2011. Lima, Perú.

Noé, Hugo (2011). "Gasto público en seguridad y justicia en Centroamérica" en Serie Estudios y Perspectivas. CEPAL. Nº132. México, D. F. Octubre.

PNUD. Informe sobre Desarrollo Humano 2013. El ascenso del Sur: Progreso humano en un mundo diverso. En:http://www.undp.org/content/dam/ undp/library/corporate/HDR/2013GlobalHDR/Spanish/HDR2013\%20 Summary\%20Spanish.pdf 
ONU. Oficina de Asuntos de Desarme, Convención Sobre la Prohibición del Empleo, Almacenamiento, Producción y Transferencia de Minas Antipersonal y Sobre su Destrucción. En: www.un.org/es/ disarmament/instruments/convention landmines.shtml

OEA. Desminado. En:www.oas.org/es/temas/minas.asp

OPANAL. (2011). Declaración de los Estados Miembros del OPANAL. S/ Inf.1071. México D. F. Septiembre

Países del ALBA acuerdan crear una "alianza militar y defensiva", en: El Universal. Venezuela. 18 octubre, 2009.

PNUD y OEA (2010). Nuestra Democracia. México DF, México, PNUD/ $\mathrm{OEA} / \mathrm{FCE} / \mathrm{AECID} / \mathrm{ACDI} / \mathrm{IFE}$

Presidentes de UNASUR crean grupo de trabajo para definir Consejo de Defensa", en: Artículos Periodísticos. 23 de mayo, 2008. En: www. comunidadandina/sudamerica.htm

Rial, Juan (2003). Hacia un sistema regional cooperativo en el Cono Sur. Ponencia 20 años de política exterior en democracia, Octubre

Revista Pensamiento Iberoamericano, $\mathrm{N}^{\circ} 10,2^{\circ}$ época, 2012/1. Clases Medias en Sociedades desiguales. (coordinación Rebeca Grynspan y Ludolfo Paramio) $306 \mathrm{pp}$.

Rojas Aravena, Francisco (1992). "América Latina en la posguerra fría: nuevas oportunidades para la cooperación para la paz", en: Relaciones Internacionales, $\mathrm{N}^{\circ} 41$, cuarto trimestre. Costa Rica, pp. 21-26

Rojas Aravena, Francisco (1995). "Williamsburg: ¿Un giro definitivo en las relaciones hemisféricas de seguridad?" En: Revista Ser en el 2000. Argentina. En: www.ser2000.org.ar

Rojas Aravena, Francisco (2010). "América Latina: Defensa y seguridad en el siglo XXI", en: Donadio, Marcela (compiladora). La reconstrucción de la seguridad nacional. Defensa, democracia y cuestión militar en América Latina. Buenos Aires: Prometeo Libros.

Rojas Aravena, Francisco (2012). "Seguridad Internacional, el Espacio y Posición de América Latina", en: Cuadernos de Estrategia, $N^{\circ} 158$, Los desafios de la seguridad en Iberoamérica. Instituto Español de Estudios Estratégicos. En: http://www.ieee.es/Galerias/fichero/cuadernos/ CE 158 DesafiosSeguridadIberoamerica.pdf

Rojas Aravena, Francisco (2013). Transformaciones globales y cambios en las relaciones de poder. Impactos en América Latina y el Caribe .Revista Nueva Sociedad $\mathrm{N}^{\mathrm{0}} 246$, julio agosto de, ISSN: 0251-3552. En: www.nuso.org Solís, Luis Guillermo y Rojas Aravena, Francisco (editores) (2008). Crimen Organizado en América Latina y el Caribe. Santiago: Ed. Catalonia, 
SG -SICA (2011). Estrategia de Seguridad de Centroamérica. Junio.

Tocar a Venezuela es Incendiar la Región” Declaraciones de Daniel Ortega. 28 de enero, 2008. En: www.alternativabolivariana.org

Ubeda, Gioconda (2010). "La agenda regional para el desarme nuclear", en: Diálogo Político. Fundación Konrad Adenauer.

Ubeda, Gioconda. (2011). Presentación Inicial de la Embajadora Gioconda Ubeda en el Foro del Organismo Internacional de Energía Atómica. 21 y 22 de noviembre de 2011. Viena.

"Un Consejo de Defensa Propio es parte de la Iniciativa del ALBA", en: Ministerio del Poder Popular para Relaciones Exteriores. 5 de febrero de 2012 